\title{
IMPROVED MEDIA FOR THE CULTURE OF NEISSERIA GONORRHOEAE
}

\author{
D. E. Macfarlane and T. F. Elias-Jones
}

\section{The City Laboratory, 23 Montrose Street, Glasgow GI IRN}

\begin{abstract}
MANY attempts have been made to devise liquid culture media that can support the growth of Neisseria gonorrhoeae. These media can be divided into two main categories: the chemically defined but complicated media such as NCDM (new chemically defined medium) (Kenny et al., 1967) and NEDF (new defined fluid medium) (Catlin, 1973), and the simpler liquid media such as ESP (enriched single phase) (Chan, Wiseman and Caird, 1975) and BP (biphasic) (Gerhardt and Hedén, 1960) which are based on an early formulation for Bacto GC Medium Base. Some of the chemically defined media have produced excellent results but are much too complex for routine use. Conversely, most of the simpler media have failed to support vigorous growth of all strains of $N$. gonorrhoeae from small inocula. These problems seemed to have been overcome by Hafiz and McEntegart (1976) who devised a new medium (ANM), based on the GCBD solid medium (Difco GC base + supplements) of Kellog et al. (1963), and with which they obtained excellent results. However the performance of ANM in our laboratory was disappointing and some of the possible reasons for this were investigated. This has led to the development of a modified liquid medium (G77L) and a corresponding solid medium (G77S) which have given better results than other gonococcal media commonly used.
\end{abstract}

\section{MATERIALS AND METHODS}

\section{Standard culture media}

Blood agar was prepared in the laboratory from Oxoid Columbia Agar Base supplemented with $5 \%$ horse blood. Chocolate agar was prepared as blood agar and heated at $75^{\circ} \mathrm{C}$ before pouring. Mueller-Hinton $+5 \%$ horse blood, Thayer Martin, and Gibco Biocult Selective Media were all obtained as poured plates from Gibco Biocult Ltd, 3 Washington Road, Paisley, Strathclyde. ANM was prepared in this laboratory according to the formula of Hafiz and McEntegart (1976). Defined supplement (DS) consisted of L-glutamine $1.0 \mathrm{~g}$, glucose $40.0 \mathrm{~g}$, ferric nitrate $0.05 \mathrm{~g}$, and cocarboxylase $0.02 \mathrm{~g}$, in $100 \mathrm{ml}$ of distilled water, as described by Hafiz and McEntegart.

\section{Modified culture media}

Modified ANM. ANM was modified by addition of DS $(2 \%)$, or horse serum $(2 \% \mathrm{v} / \mathrm{v})$ or antibiotics (vancomycin $3 \mu \mathrm{g} / \mathrm{ml}$, trimethoprim $8 \mu \mathrm{g} / \mathrm{ml}$ and colistin $5 \mu \mathrm{g} / \mathrm{ml}$.

Medium $G 77 B$. This basal medium was slightly modified from Difco GC Base and ANM and consisted of Proteose Peptone No. 3 (Difco) $15.0 \mathrm{~g}, \mathrm{~K}_{2} \mathrm{HPO}_{4}$ (AnalaR) $4.0 \mathrm{~g}, \mathrm{KH}_{2} \mathrm{PO}_{4}$ (AnalaR) $1.0 \mathrm{~g}, \mathrm{NaCl}$ (AnalaR) $5.0 \mathrm{~g}$, soluble starch (BDH) $1.0 \mathrm{~g}$, distilled water to $1000 \mathrm{ml}$. This base was sterilised by autoclaving at $115^{\circ} \mathrm{C}$ for $15 \mathrm{~min}$. and stored at $4^{\circ} \mathrm{C}$.

Modifications of $\mathrm{G} 77 \mathrm{~B}$ were as follows: $\mathrm{G} 77 \mathrm{BS}=\mathrm{G} 77 \mathrm{~B}+1.0 \%$ Bacto Agar; $\mathrm{G} 77 \mathrm{~B} 1=\mathrm{G} 77 \mathrm{~B}+0.3 \%$ Yeast Extract $\quad($ Difco) $; \mathrm{G} 77 \mathrm{BS} 1=\mathrm{G} 77 \mathrm{BS}+0.3 \%$ yeast extract; $\mathrm{G} 77 \mathrm{~B} 2=\mathrm{G} 77 \mathrm{~B} 1+0 \cdot 2 \%$ glucose.

Medium $G 77 \mathrm{~L}$. The following formulation was eventually selected as the best for cultivation of $N$. gonorrhoeae: Proteose Peptone No. 3 (Difco) $15.0 \mathrm{~g}, \mathrm{~K}_{2} \mathrm{HPO}_{4}$ (AnalaR) $4.0 \mathrm{~g}, \mathrm{KH}_{2} \mathrm{PO}_{4}$ (AnalaR) $1.0 \mathrm{~g}, \mathrm{NaCl}$ (AnalaR) $5.0 \mathrm{~g}$, soluble starch $(\mathrm{BDH}) 1.0 \mathrm{~g} . \mathrm{NaHCO} 32.0 \mathrm{~g}, \mathrm{Fe}\left(\mathrm{NO}_{3}\right)_{3} 2.0$ $\mathrm{mg}$, phenol red $(0.2 \%) 12 \mathrm{ml}$, distilled water to $965 \mathrm{ml} ; p \mathrm{H}$ adjusted to $7.4-7.5$ with $1 \mathrm{M} \mathrm{NaOH}$ if 
required. Before autoclaving at $115^{\circ} \mathrm{C}$ for $15 \mathrm{~min}$., containers of medium were sealed to prevent loss of $\mathrm{CO}_{2}$. The sterilised medium was stored at $4^{\circ} \mathrm{C}$ and, before use, each $965 \mathrm{ml}$ was supplemented with $20 \mathrm{ml}$ of filter-sterilised $25 \%$ Yeast Extract (Difco) and $4 \mathrm{ml}$ of filter-sterilised $50 \%$ glucose solution. An optional antibiotic supplement consisted of (per litre) trimethoprim $2.0 \mathrm{mg}$, vancomycin $2.5 \mathrm{mg}$, polymixin B $5.0 \mathrm{mg}$.

In the development of the formulae for G77L, several of the above and additional ingredients were tested at other concentrations, viz, yeast extract 0.6 and $1.2 \%(\mathrm{w} / \mathrm{v}), \mathrm{NaHCO}_{3} 1.0$ and 1.5 $\mathrm{g} / \mathrm{l}$, glucose $0 \cdot 2,0 \cdot 4,0.6$ and $1.0 \%(\mathrm{w} / \mathrm{v})$, glutamine $10 \mathrm{mg} / \mathrm{l}$.

Medium $G 77 S$. The formula of $\mathrm{G} 77 \mathrm{~L}$ was slightly modified to yield a corresponding solid medium. The $\mathrm{NaHCO}_{3}$ concentration was reduced from 2 to $1 \mathrm{~g} / 1$ and Bacto Agar $10 \mathrm{~g}$ was added to each litre of medium before autoclaving. The supplements were added to the molten medium after cooling to $42^{\circ} \mathrm{C}$. The volume of $50 \%$ glucose was increased from $4 \mathrm{ml}$ to $30 \mathrm{ml}$ with a corresponding reduction in the volume of distilled water. After the medium had been poured, the plates were dried at $45^{\circ} \mathrm{C}$ and stored at $4^{\circ} \mathrm{C}$.

\section{Measurement of growth and survival of N. gonorrhoeae}

In liquid media. Suspensions of freshly isolated and stock strains of $N$. gonorrhoeae were prepared in phosphate-buffered saline and fixed volumes were dispensed into the various liquid test media which were incubated at $37^{\circ} \mathrm{C}$. Samples were removed at suitable intervals, dilutions were prepared and $0.5-\mathrm{ml}$ inocula flooded over the surface of blood-agar plates which were incubated at $37^{\circ} \mathrm{C}$ in an atmosphere of air $+5 \% \mathrm{CO}_{2}$ for $48 \mathrm{~h}$, after which colonies were counted.

On solid media. Suspension of different strains of $N$. gonorrhoeae were flooded over solid media in petri dishes, and incubated and their size were compared with those on control plates of blood agar which had been flooded with samples of the same inocula, and incubated in parallel.

\section{RESULTS}

\section{Growth of N. gonorrhoeae in ANM with or without DS}

Growth curves for 15 strains of $N$. gonorrhoeae in ANM, and ANM +DS at $37^{\circ} \mathrm{C}$ and at $22^{\circ} \mathrm{C}$ showed that the strains could be divided into three main categories, i.e., those that grew in plain ANM (7 strains), those that grew only in ANM + DS (4), and those that did not grow in either (4). Growth of a representative strain from each group is depicted in fig. 1. In all cultures the number of colony-forming units (c.f.u.) fell by $c .90 \%$ in the first $2 \mathrm{~h}$. This was followed by a period of rapid growth of some strains which lasted $4-6 \mathrm{~h}$, and then by a more gradual increase in numbers, reaching a maximum at 3 days. Against all strains that grew in ANM, the addition of DS had a slight inhibitory effect, e.g., strain 072 in fig. 1. Strain 046 grew in the presence of DS but survived for only $c$. $70 \mathrm{~h}$ without the supplement. Strain 041 multiplied for $2 \mathrm{~h}$ after an initial decrease in numbers, but failed to increase the number of c.f.u. above the original inoculum, and organisms were not recovered after $90 \mathrm{~h}$ in either medium. The survival of these same three strains at $22^{\circ} \mathrm{C}$ is depicted in fig. 2. After a rapid decrease in numbers during the first $2 \mathrm{~h}$, most strains produced some growth from 2 to $6 \mathrm{~h}$, but there were no viable organisms at $48 \mathrm{~h}$. The brief spurt of growth at $22^{\circ} \mathrm{C}$ may have been due to the medium being at $37^{\circ} \mathrm{C}$ when inoculated, and for a short time thereafter.

Seventy-eight routine isolates of $N$. gonorrhoeae were tested in ANM with an inoculum of $>10^{6}$ c.f.u./ml, growth being measured by turbidity. Of these, 37 failed to grow in ANM and 19 failed to grow in ANM + DS. Of the strains that grew in either medium, the lowest starting inoculum that consistently gave growth was around $1.5 \times 10^{3}$ c.f.u. $/ \mathrm{ml}$.

Continued investigation of the effect of DS confirmed earlier observations that the strains that grew in ANM were slightly inhibited by the addition of the supplement (table I). A similar effect was noted on the addition of antibiotics (table I). In a simple attempt to improve the medium, it was supplemented with $2 \%$ horse serum and although initially growth was somewhat retarded, the maximum yield of organisms was slightly improved (table I). 


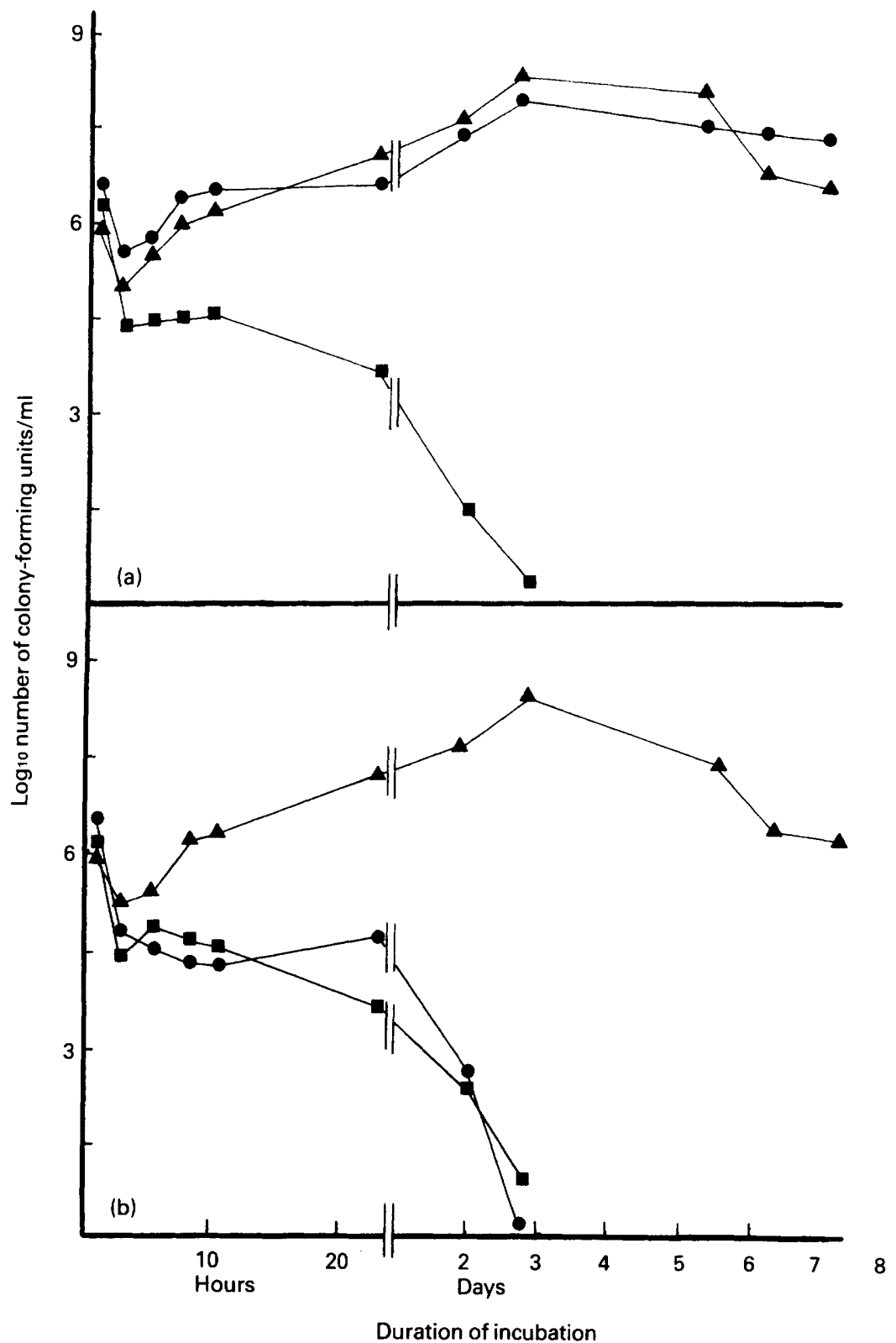

FIG. 1. Growth of representative strains of Neisseria gonorrhoeae in (a) ANM + DS and (b) ANM alone at $37^{\circ} \mathrm{C}$. Strain 072 $\triangle$, strain 041

\section{Development of improved media}

To explore the effects of various components of culture media on the growth of $N$. gonorrhoeae, the basal media G77B and G77BS were prepared and then supplemented with various additives. Table II shows that yeast extract greatly improved growth on solid medium, the maximal effect being achieved at $0 \cdot 3 \%$. Liquid media gave similar results. 


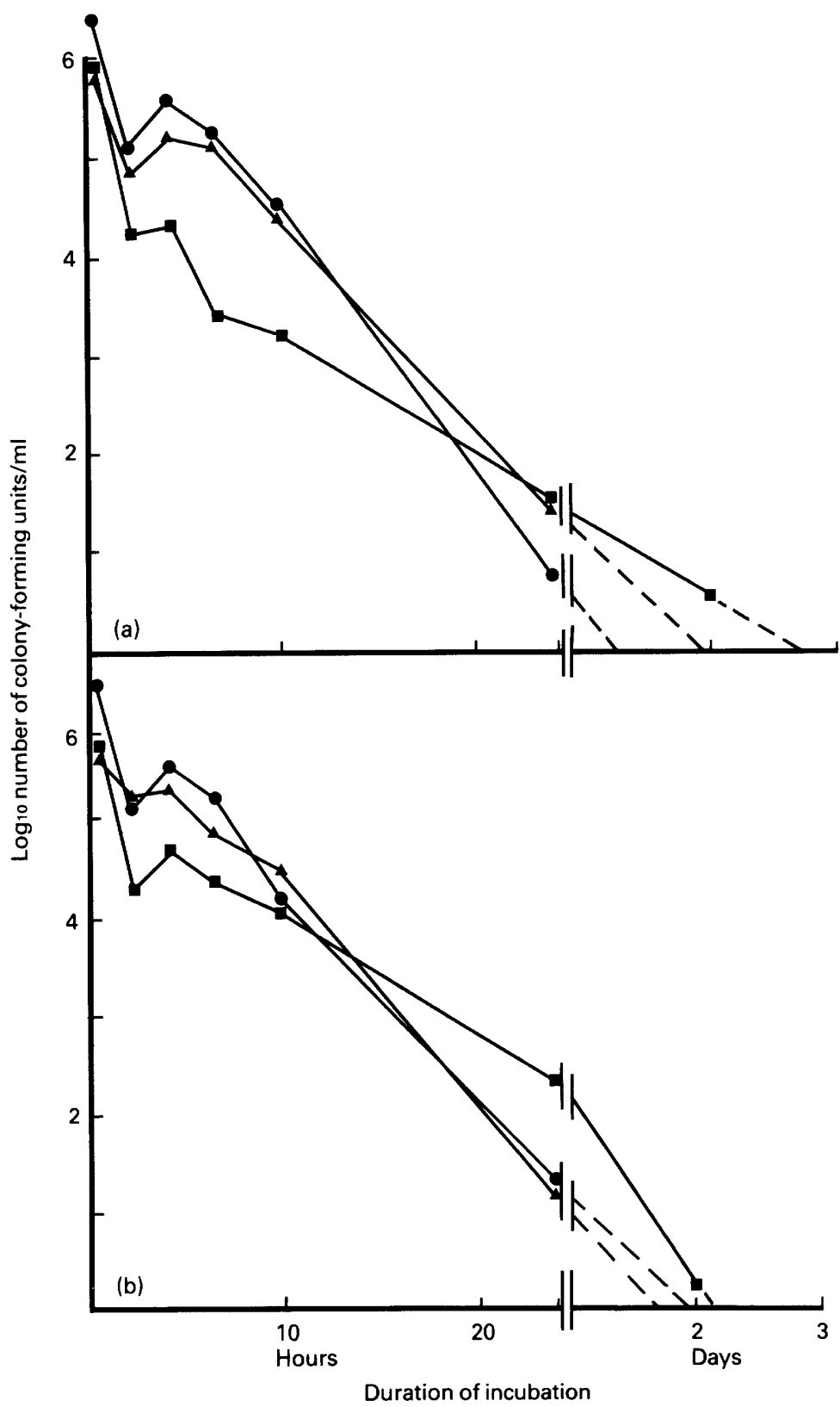

FIG. 2.-Survival of strains of Neisseria gonorrhoeae in (a) ANM and (b) ANM + DS at $22^{\circ} \mathrm{C}$. Foot notes as in fig. 1.

Phenol red was tested for inhibition of growth but no effect was noted at the concentration used, $24 \mathrm{mg} / \mathrm{l}$; it acted as an indicator for the production of lactic acid in media containing glucose and facilitated control of $p \mathrm{H}$ changes due to loss of $\mathrm{CO}_{2}$.

Glucose improved the growth of test strains in the liquid medium, maximum effect being achieved with a concentration of $2 \mathrm{~g} / \mathrm{l}$ (fig. 3 ). On the corresponding solid media, fermentation 
TABLE I

Growth of a representative strain of Neisseria gonorrhoeae in ANM alone and with various additives

\begin{tabular}{c|cccc}
\hline $\begin{array}{c}\text { Duration of } \\
\text { incubation } \\
\text { (h) }\end{array}$ & \multicolumn{4}{|c}{ Number of colony-forming units/ml in ANM plus } \\
\cline { 2 - 5 } no additives & $2 \%$ DS & antibiotics* & $2 \%$ horse serum \\
\hline 0 & $1.3 \times 10^{6}$ & $1.3 \times 10^{6}$ & $1.3 \times 10^{6}$ & $1.3 \times 10^{6}$ \\
$2 \frac{1}{2}$ & $1.9 \times 10^{5}$ & $1.6 \times 10^{5}$ & $1.1 \times 105$ & $1.9 \times 10^{5}$ \\
5 & $1.2 \times 10^{6}$ & $1.5 \times 10^{5}$ & $6.4 \times 10^{5}$ & $7.4 \times 10^{5}$ \\
8 & $3.2 \times 10^{6}$ & $1.6 \times 10^{6}$ & $1.4 \times 10^{6}$ & $3.2 \times 10^{6}$ \\
24 & $3.8 \times 10^{7}$ & $2.1 \times 10^{7}$ & $2.6 \times 10^{6}$ & $3.8 \times 10^{7}$ \\
48 & $1.5 \times 10^{8}$ & $5.1 \times 10^{7}$ & $9.0 \times 10^{7}$ & $2.2 \times 10^{8}$ \\
72 & $2.4 \times 10^{10}$ & $1.6 \times 10^{10}$ & $2.5 \times 10^{10}$ & $4.1 \times 10^{10}$ \\
144 & $3.3 \times 10^{10}$ & $2.9 \times 10^{10}$ & $2.0 \times 10^{10}$ & $2.4 \times 10^{10}$ \\
\hline
\end{tabular}

ANM = medium of Hafiz and McEntegart (1976); DS=defined supplement (see Materials and methods). * Vancomycin $3 \mu \mathrm{g} / \mathrm{ml}$, trimethoprim $8 \mu \mathrm{g} / \mathrm{ml}$ and colistin $5 \mu \mathrm{g} / \mathrm{ml}$.

\section{TABLE II}

Growth from similar inocula of four strains of Neisseria gonorrhoeae on medium G77B1 with various concentrations of yeast extract, after incubation for $24 \mathrm{~h}$ at $37^{\circ} \mathrm{c}$ in air $+5 \% \mathrm{CO}_{2}$

\begin{tabular}{|c|c|c|c|c|c|c|c|c|}
\hline \multirow{3}{*}{ Strain no. } & \multicolumn{8}{|c|}{$\begin{array}{c}\text { Average number and size of colonies after incubation } \\
\text { on } \mathrm{G} 77 \mathrm{~B} \text { containing indicated addition of } \\
\text { yeast extract }\end{array}$} \\
\hline & \multicolumn{2}{|c|}{ None } & \multicolumn{2}{|c|}{$0.3 \%$} & \multicolumn{2}{|c|}{$0.6 \%$} & \multicolumn{2}{|c|}{$1 \cdot 2 \%$} \\
\hline & Number & $\begin{array}{l}\text { Diameter } \\
(\mathrm{mm})\end{array}$ & Number & $\begin{array}{l}\text { Diameter } \\
(\mathrm{mm})\end{array}$ & Number & $\begin{array}{l}\text { Diameter } \\
(\mathrm{mm})\end{array}$ & Number & $\begin{array}{l}\text { Diameter } \\
(\mathrm{mm})\end{array}$ \\
\hline 868 & 0 & 0 & 168 & 0.75 & 100 & 0.75 & 48 & 0.75 \\
\hline 771 & 0 & 0 & 220 & 1.00 & 238 & 1.00 & 250 & $1 \cdot 00$ \\
\hline 841 & 7 & 0.5 & 840 & 1.00 & 761 & 1.00 & 520 & 1.00 \\
\hline 932 & 13 & 0.5 & 570 & 1.00 & 541 & 1.00 & 497 & 1.00 \\
\hline
\end{tabular}

of glucose, as indicated by the colour change due to production of lactic acid, was not observed at glucose concentrations below $15 \mathrm{~g} / \mathrm{l}$, whereas in the liquid medium, a glucose concentration of $1.5 \mathrm{~g} / \mathrm{l}$ led to production of acid. This difference was presumed to be due to the "Pasteur effect", whereby glycolysis is more rapid and leads to the production of lactic acid instead of $\mathrm{CO}_{2}+\mathrm{H}_{2} \mathrm{O}$ in the anaerobic environment of the depths of the liquid medium.

$\mathrm{NaHCO}_{3}$ at concentrations of $1 \mathrm{~g}, 1.5 \mathrm{~g}$ and $2 \mathrm{~g} / \mathrm{l}$ improved the growth of all strains tested but to variable extents. The effect of $\mathrm{NaHCO}_{3} 2 \mathrm{~g} / \mathrm{l}$ on the growth of a representative strain of $N$. gonorrhoeae is shown in fig. 4, maximum effect being achieved at this concentration. A similar improvement was noted in the solid medium but the effect was not as obvious. The bicarbonate was not able to act as the sole source of $\mathrm{CO}_{2}$ in sealed plates and therefore the solid medium had to be incubated in the normal fashion in jars with an atmosphere of air $+5 \% \mathrm{CO}_{2}$.

Ferric nitrate $3 \mathrm{mg} / \mathrm{l}$ had no significant effect on any of the batches of liquid or solid media tested (fig. 4 and table III). Glutamine at a concentration of $10 \mathrm{mg} / \mathrm{l} \mathrm{had}$ an inhibitory effect in the liquid and on the solid media (fig. 4 and table III). Antibiotics had a consistently deleterious effect on all batches of liquid and solid media (fig. 4 and table III). The G77Bl medium was more prone to this effect than the blood agar used as the control (table III).

It was noted during preparation of the modified medium that temperature had an important 


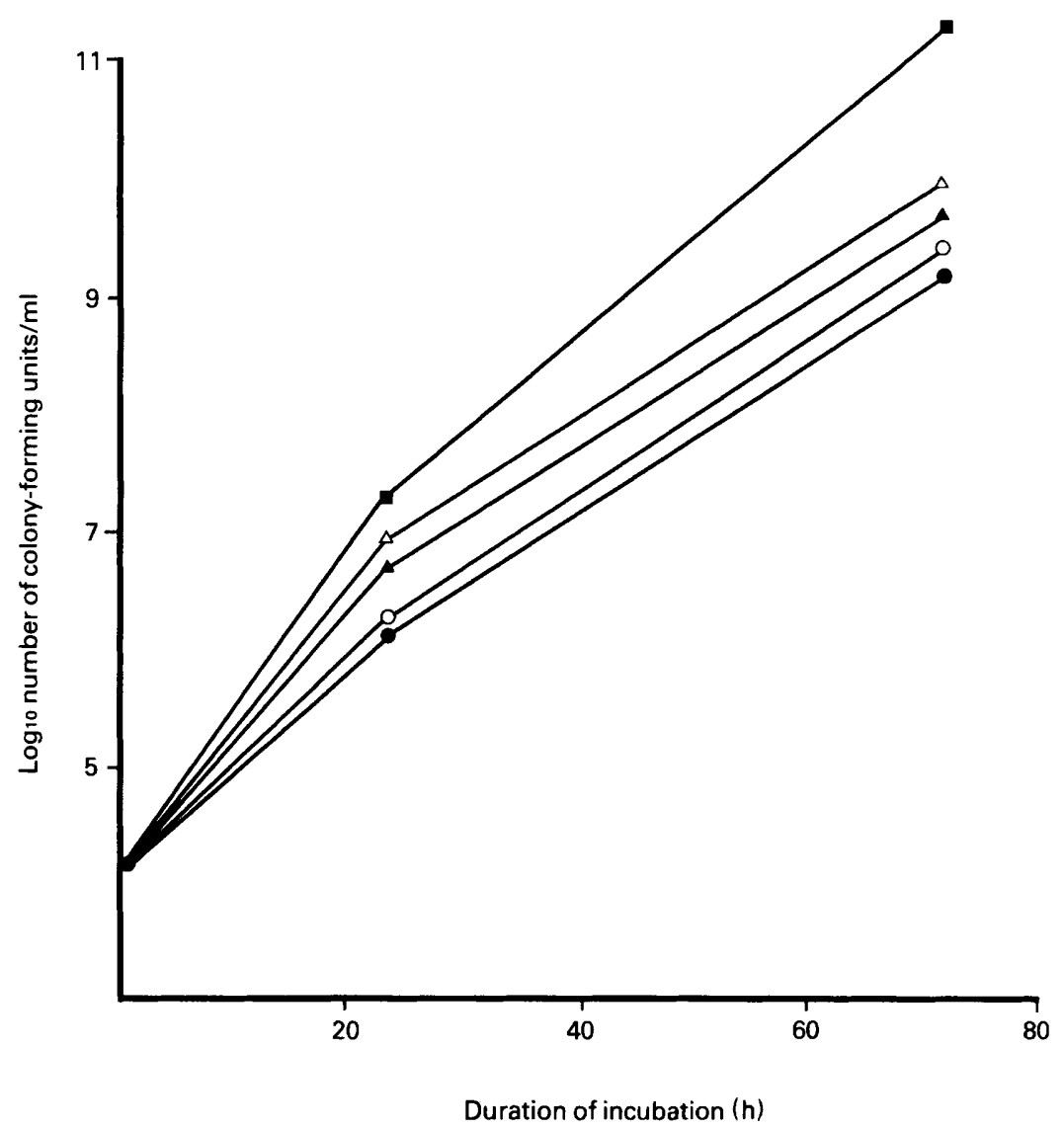

FIG. 3.-Effect of concentration of glucose on growth of Neisseria gonorrhoeae strain 039 in medium G77B1. No glucose $0 \longrightarrow 0,2 \mathrm{~g} / 1 \backsim \longrightarrow, 4 \mathrm{~g} / \mathrm{l} \Delta \longrightarrow \Delta, 6 \mathrm{~g} / \mathrm{l} \iota \longrightarrow$

effect on its constituents. Autoclaving above $115^{\circ} \mathrm{C}$ caused deterioration of the medium and in an attempt to surmount this problem, filter sterilisation was tried. But this also had a detrimental effect. Thus the base has to be heated but the temperature is critical. A similar problem was encountered when drying the plates of solid medium. It was observed that overnight drying at $37^{\circ} \mathrm{C}$ had an adverse effect and the plates were therefore dried in a warm air oven at $45^{\circ} \mathrm{C}$ for a minimal time and stored at $4^{\circ} \mathrm{C}$.

Comparison of finally formulated media with other media commonly used for growth of $N$. gonorrhoeae

From the above observations on the effect of the various additives on the basal medium G77B, a liquid medium G77L and corresponding solid medium G77S were developed. These two completed media were tested against 97 consecutive isolates of N. gonorrhoeae, of which 96 grew well in both. One strain failed to grow on G77S but grew, albeit poorly, on blood agar. Investigation revealed that this strain was sensitive to trimethoprim, and although the same concentration $(3 \mu \mathrm{g} / \mathrm{ml})$ was used in blood agar and in $\mathrm{G} 77 \mathrm{~S}$, the effect of the trimethoprim seemed considerably stronger in the latter. Medium G77S was compared with several of the more commonly used media for ability to support the growth of $N$. gonorrhoeae. It was found 


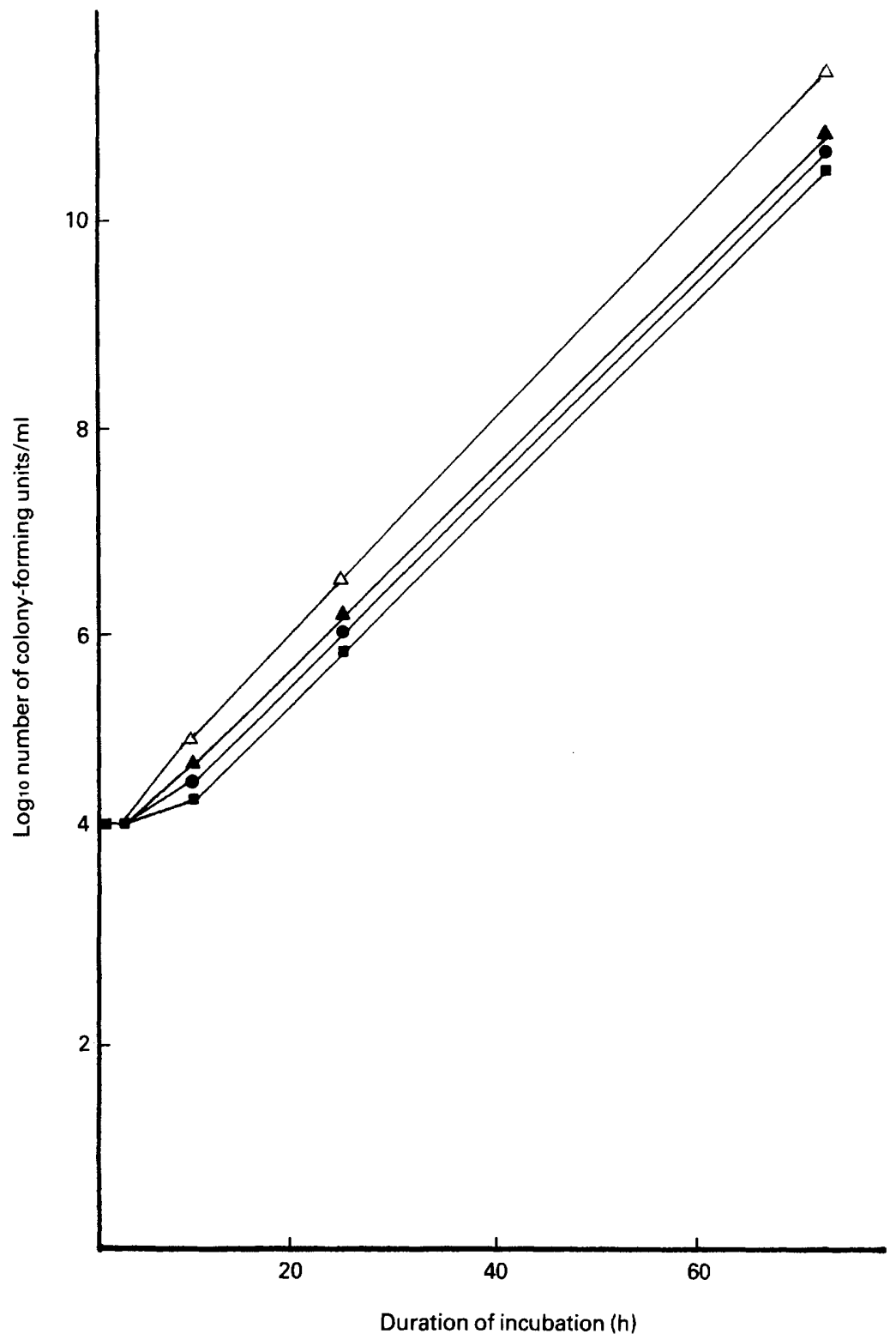

FIG. 4.-Effect of various additives to medium on the growth of a representative strain of Neisseria

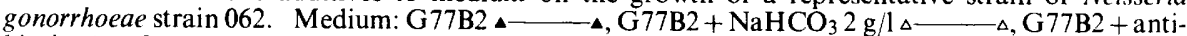
biotics (see footnote to table I) $\left.\longrightarrow, \mathrm{G} 77 \mathrm{~B} 2+\mathrm{Fe}\left(\mathrm{NO}_{3}\right)_{3} 3 \mathrm{mg} / \mathrm{l}\right\lrcorner-\Delta, \mathrm{G} 77 \mathrm{~B} 2+$ glutamine 10 $\mathrm{mg} / \mathrm{l} \bullet$

to be superior in the number of colony-forming units obtained from the same inoculum, and in the size of the resulting colonies (table IV). Medium G77L, when tested for ability to support growth from small inocula, consistently yielded positive results from concentrations as low as 5 c.f.u./ml. Its superiority over ANM + DS is clearly shown in fig. 5 .

Horse serum at concentrations of $2 \%$ and $4 \%$ was added to G $77 \mathrm{~S}$ to determine whether the growth of $N$. gonorrhoeae could be further improved. However the addition of serum reduced 

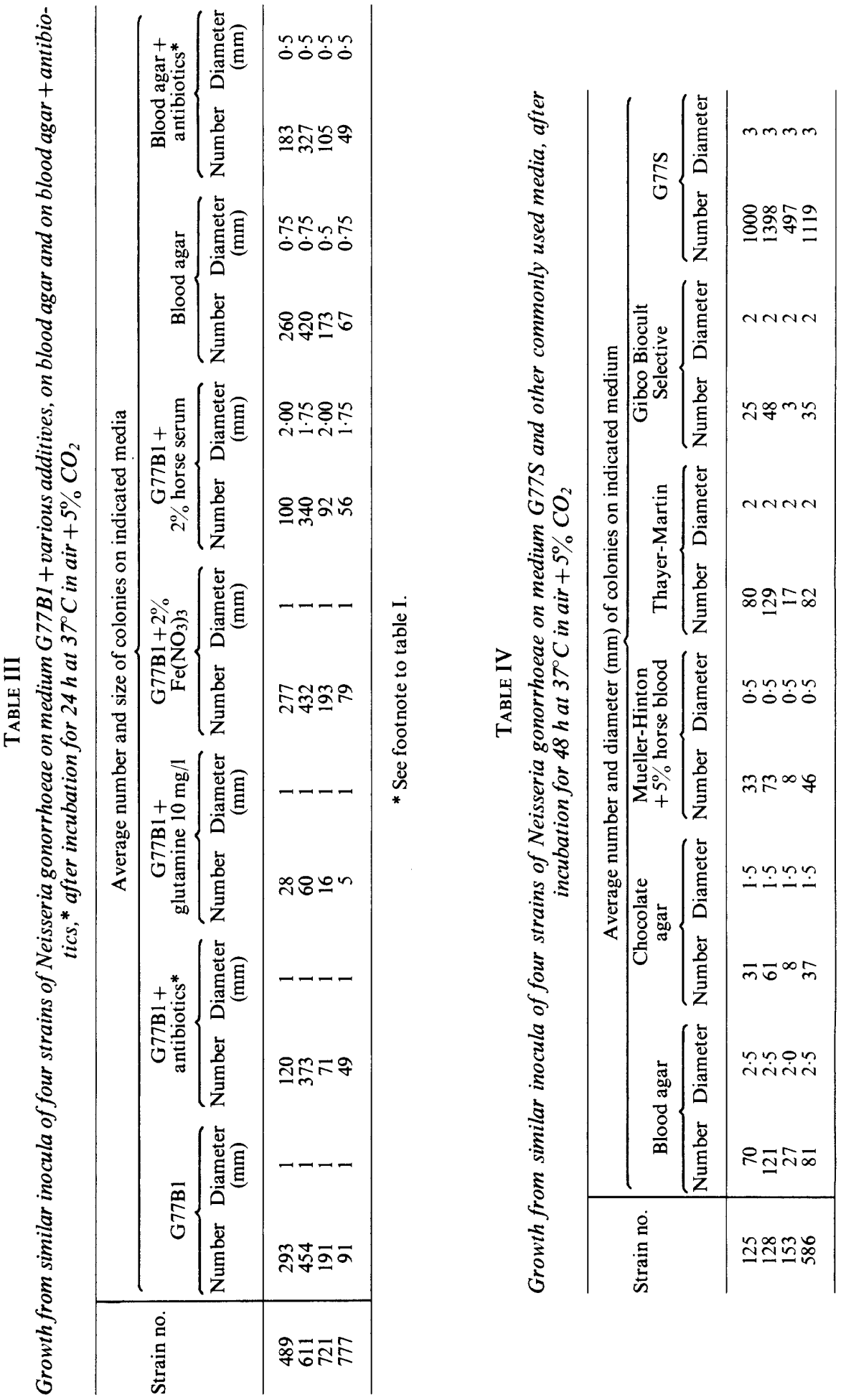


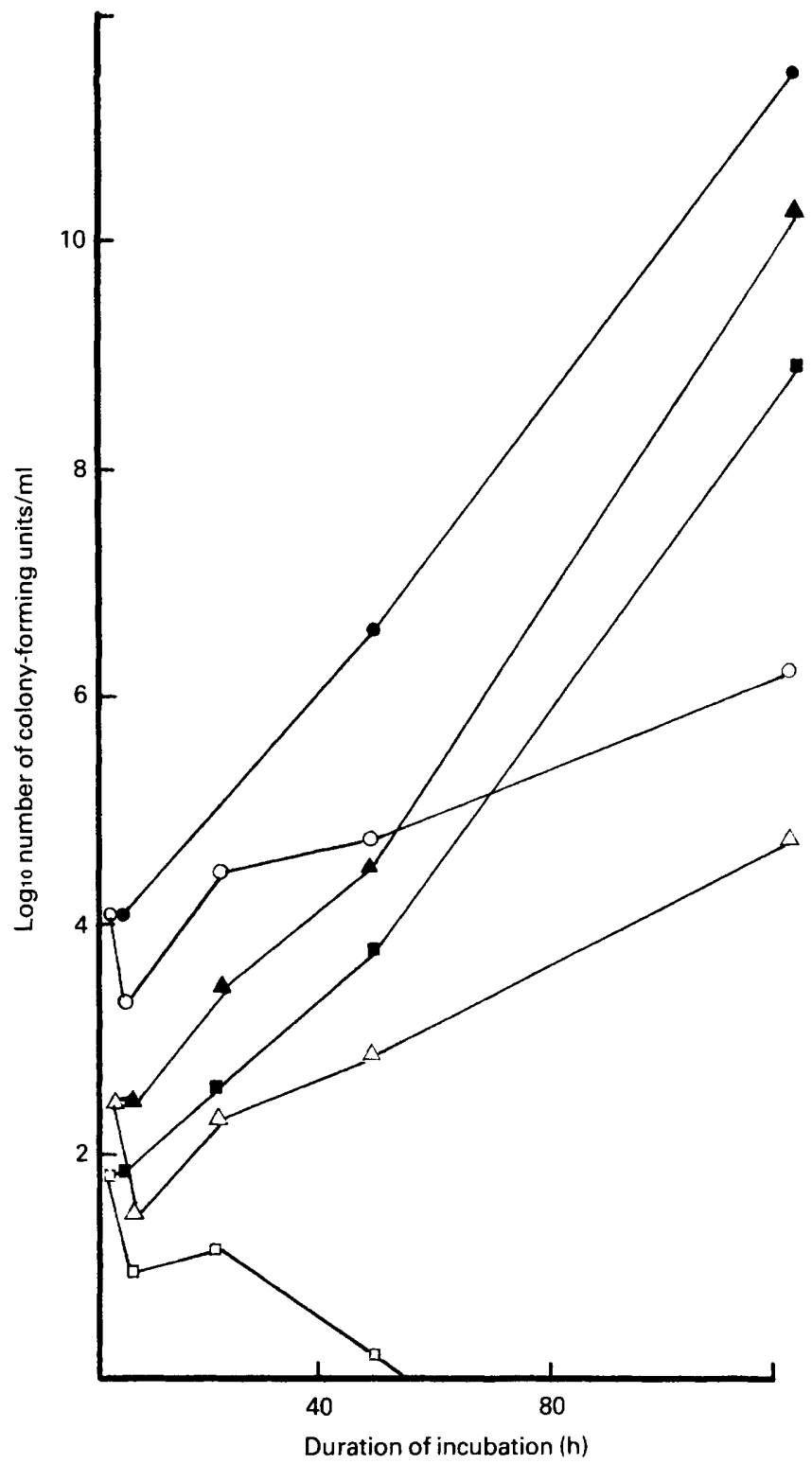

FIG. 5.-Growth of three representative strains of Neisseria gonorrhoeae in ANM + DS and in medium G77L. Strain 590 in ANM + DS $\circ \longrightarrow 0$, in G77L $-\bullet$; strain 498 in ANM + DS $\triangle \longrightarrow \triangle$. in G $77 \mathrm{~L} \_$; strain 694 in ANM + DS $\square \longrightarrow$ D, 694 in G77L

the number of colonies but increased their size. A similar result was observed with ANM, in which horse serum initially inhibited growth but increased the final yield (table I).

\section{Discussion}

The poor results obtained with ANM were probably because the amount of bicarbonate was insufficient to produce a significant amount of $\mathrm{CO}_{2}$. Therefore strains of $N$. gonorrhoeae 
requiring $\mathrm{CO}_{2}$ for growth would need additional gassing of the medium. Chan et al (1975) failed to grow their two test strains of $N$. gonorrhoeae in a liquid medium without $\mathrm{CO}_{2}$, whereas both strains grew in the presence of $6 \% \mathrm{CO}_{2}$. Catlin (1973), using the complex liquid medium NEDF, noted that two out of seven strains of $N$. gonorrhoeae required $\mathrm{CO}_{2}$ for growth. $\mathrm{He}$ also observed that strains requiring increased $\mathrm{CO}_{2}$ tension for growth underwent a 10 -fold drop in the number of viable organisms during the first $2 \mathrm{~h}$ (cf. figs. 1 and 2) when grown in air. Hafiz and McEntegart (1976) found that increased $\mathrm{CO}_{2}$ had only a slight effect on the growth of $N$. gonorrhoeae in ANM and for this reason we tested this medium only in air. Incubation in an atmosphere of air $+10 \% \mathrm{CO}_{2}$ might have given better results.

ANM contains proteose peptone as its only source of vitamins, aminoacids, nucleotides and other essential growth factors. Because the medium is sterilised by autoclaving, some heatlabile constituents may be destroyed and the medium may therefore be deficient in unstable aminoacids such as glutamine, many of the vitamins, especially the B complex, and other labile nutrients. Thus strains of $N$. gonorrhoeae requiring glutamine (Lankford and Snell, 1943), thiamine pyrophosphate (Lankford and Skeggs, 1946) or other growth factors affected by heat (Catlin 1973) may not grow in ANM. The defined supplement contained the constituents described by Lankford (1950) with the addition of ferric nitrate (Kellogg et al 1963). Of these constituents the glucose should have no effect because there is adequate glucose in ANM (fig. 4) and we could not demonstrate a beneficial effect from the addition of ferric nitrate. The remaining two constituents, glutamine and cocarboxylase, are, as previously indicated, essential metabolites for some strains and therefore their addition to the medium would be expected to increase the number of strains able to grow in the medium but not necessarily to improve the growth of other strains.

The modifications developed in this study to overcome the failings of ANM were in most instances successful (fig. 5). The increased bicarbonate concentration enabled the liquid medium to produce enough $\mathrm{CO}_{2}$ and thus eliminated the need for gassing. Because of the possible leakage of $\mathrm{CO}_{2}$ during autoclaving or during storage, and the increased sensitivity of metabolites, such as aminoacids, to the effect of heat in alkaline media, it would perhaps be better to add the bicarbonate from a sterile solution after autoclaving or immediately before use.

The failure to achieve improved growth by the addition of ferric nitrate was somewhat unexpected (Kellogg et al., 1968), but may have been due to the medium already containing enough iron from the proteose peptone and yeast extract, both of which contain ferric ions. However, because the concentration of ferric ions in these two components may vary from batch to batch, we decided to include ferric nitrate in the final formulation.

The rapid fermentation of glucose in the liquid and solid media suggests that these media may be useful as fermentation media for neisseria. It seems highly unlikely that the small amount of yeast extract in the medium would interfere with fermentation reactions. The inclusion of glucose and phenol red has the additional benefit of allowing differentiation between $N$. gonorrhoeae and $N$. catarrhalis on primary isolation, a problem that is becoming more important with the increased submission of throat swabs for examination for gonococci. The antibiotic mixture performed satisfactorily, although slight inhibition of growth was consistently observed. The one instance in which it caused a growth failure was shown to be due to increased sensitivity of the strain to trimethoprim, and drew attention to the well documented problem of using this antimicrobial agent in culture media. Although the concentration of trimethoprim was identical in the modified media and in blood agar, the effective concentration was lower in the blood agar because of thymidine or other products of folate metabolism. Thus there was growth of the unusual strain of $N$. gonorrhoeae on blood agar but not in the new medium. For this reason, the trimethoprim concentration in the final formula was reduced to 2 $\mu \mathrm{g} / \mathrm{ml}$. It seems that the inconsistent performance of trimethoprim, especially in media containing blood or blood products, may present problems if too high a concentration is used.

The inhibitory effect of glutamine as a supplement was taken as indicating that the yeast extract was an adequate source of this aminoacid, because many aminoacids are toxic if present in excess. This may also explain why the DS was found to be inhibitory when added to ANM. It is interesting to note that Lankford (1950) recommended glutamine $0.5 \mathrm{~g} / 100 \mathrm{ml}$ of supplement whilst Hafiz and McEntegart increased this concentration to $1 \mathrm{~g} / 100 \mathrm{ml}$. 
Although maximum improvement of growth was obtained with a concentration of $0 \cdot 3 \%$ of yeast extract we decided to increase the concentration to $0.5 \%$ in the final formulation to compensate for any deterioration in the yeast extract before use.

The effect of $2 \%$ horse serum on the solid medium presents a dilemma that is difficult to resolve, for while there was more luxuriant growth-larger colonies and more rapid fermentation - the actual number of colonies was reduced.

\section{SUMMARY}

The ANM medium of Hafiz and McEntegart (1976) was found to be deficient in ability to support the growth of various strains of $N$. gonorrhoeae. Strains that did grow required a large starting inoculum which invariably suffered a substantial drop in the number of viable organisms during the first $2 \mathrm{~h}$. Investigation of the various deficiencies led to the development of liquid (G77L) and solid (G77S) media which were shown to have several advantages over existing media for the cultivation of $N$. gonorrhoeae. These media, which are simple to prepare, do not contain blood or serum and yet gave excellent growth. The inclusion of antibiotics, glucose and phenol red allowed the selective isolation and partial identification of $N$. gonorrhoeae from routine specimens. These media also gave good results in fermentation tests for the identification of neisseriae.

\section{REFERENCES}

Catlin, B. W. 1973. Nutritional profiles of Neisseria gonorrhoeae, Neisseria meningitidis and Neisseria lactamica in chemically defined media and the use of growth requirements for gonococcal typing. J. infect. Dis., 128, 178.

Chan, K., Wiseman, G. M. AND CaIRD, J. D. 1975. Cultivation of type 1 Neisseria gonorrhoeae in liquid media. Br. J. ven. Dis., 51, 382.

GerhardT, P. AND HedÉN, C. G. 1960. Concentrated culture of gonococci in clear liquid medium. Proc. Soc. exp. Biol. Med., 105, 49.

Hafiz, S. AND MCEnTEgart, M. G. 1976. Prolonged survival of Neisseriagonorrhoeae in a new liquid medium. Br. J. ven. Dis., 52, 381.

KellogG, D. S., Cohen, I. R., Norins, L. C., Schroeter, A. L. And Reising, G. 1968. Neisseria gonorrhoeae. II. Colonial variation and pathogenicity during 35 months in vitro. J. Bact., 96, 596.

Kellogg, D. S., Peacock, W. L., Deacon, W. E., Brown, L. and Pirkle, C. I. 1963. Neisseria gonorrhoeae. I. Virulence genetically linked to clonal variation. J. Bact., 85, 1274.

Kenny, C. P., Ashton, F. E., Diena, B. B. And Greenberg, L. 1967. A chemically defined protein-free liquid medium for the cultivation of some species of Neisseria. Bull. Wld Hlth Org., 37, 569.

LANKFORD, C. E. 1950. Chemically defined nutrient supplements for gonococcus culture media. Bact. Proc., 50, 40.

LANKFORD, C. E. AND SKAGGS, P. K. 1946. Cocarboxylase as a growth factor for certain strains of Neisseria gonorrhoeae. Arch. Biochem., 9, 265.

LANKFoRd, C. E. AND SNELL, E. E. 1943. Glutamine as a growth factor for certain strains of Neisseria gonorrhoeae. J. Bact., 45, 410. 